\title{
Past land-use and land-cover change: the challenge of quantification at the subcontinental to global scales
}

\author{
Marie-José Gaillard', K.D. Morrison², M. Madella ${ }^{3}$ and N. Whitehouse ${ }^{4}$
}

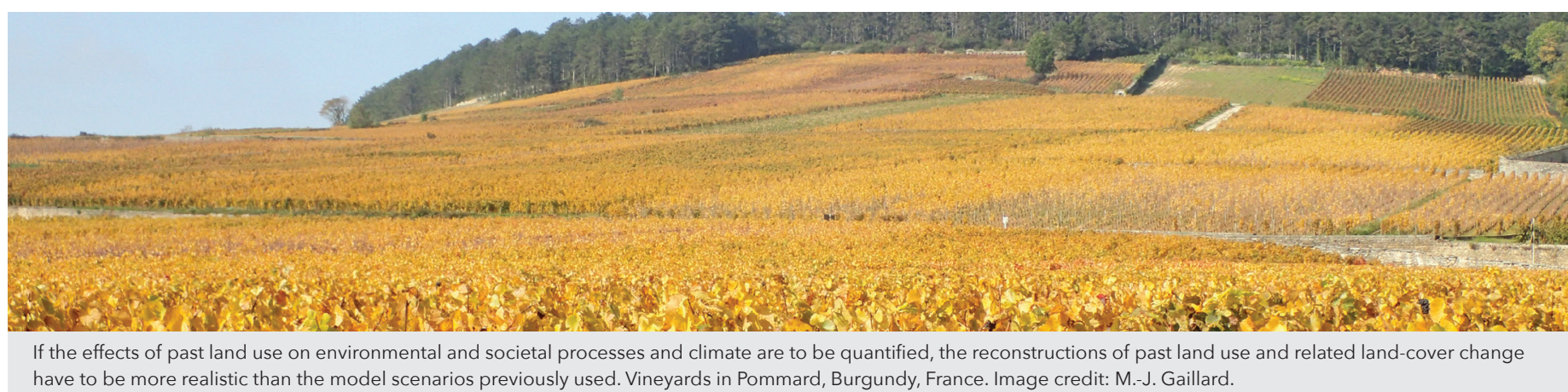

Land-use change has influenced, and influences, many aspects of the environment such as pedogenesis, soil erosion, hydrology, vegetation, lakes' and rivers' nutrient status, microclimate and, last - but not least - regional and global climate. It is still a challenge, however, to quantify land-use change in the past and its effect on past environment through time and across space. Such knowledge is necessary for the development of sustainable landscape management and land-use strategies in line with the challenge of climate warming mitigation.

It is widely accepted that plant cover on Earth is part of the climate system and anthropogenic land-cover change (as a consequence of landuse change) may imply a complex combination of biogeochemical and biogeophysical processes. The size and sign (warming or cooling) of the net effect of anthropogenic land-cover change on global and regional climate is, however, still a matter of debate (Strandberg et al. 2014; Gaillard et al. 2015). The first coordinated database of land-cover (basically deforestation) maps, at 50-year intervals, since $1700 \mathrm{CE}$ for climate modeling studies was led by Leemans and collaborators, and discussed for the first time at a workshop organized by PAGES Biome 300 (Leemans et al. 2000). The latter was part of the PAGES HITE working group initiated by Frank Oldfield (Oldfield et al. 2000), the first PAGES activity dealing with the human dimension of climate change. It resulted in the now well-known HYDE Database (History Database of the Global Environment) of past land use and land cover (Klein Goldewijk 2001). Since then, HYDE has been updated and improved regularly to the latest version (3.2; Klein Goldewijk et al. 2017) and has been the most-used database on land use by climate modelers. HYDE's and other scenarios of past land use, however, tend to overlook socio-cultural effects such as technology or diet, which are as important as the physical environment in determining land-use strategies. Improving the records of socio-cultural characteristics behind the diverse approaches of past societies to environmental exploitation will augment our understanding of past, present and future dynamics of our planet.
In this issue, we have gathered contributions that illustrate the challenge of reconstructing past land use and land cover at different spatial scales (from local to global). The PAGES LandCover6k working group's primary goal is to use pollen, archaeological (both material culture and biological remains) and historical data to provide quantitative information on past land cover and land use to evaluate and improve Anthropogenic Land-Cover Change (ALCC) scenarios for paleoclimate modeling. Archaeology and history-based land-use maps with quantifiable attributes at the global scale, plus pollen-based reconstructions of past land cover at a subcontinental and continental scale using the REVEALS model (Sugita 2007) or alternative methods, are major products of the working group. In addition to the need for global modeling studies of the Earth system over past millennia, there is also scope for improved interregional comparisons of land-use history and for data syntheses that will allow better understanding of the interconnected histories of land use and social transformations over time.

The issue opens with papers on the need for realistic reconstructions of past anthropogenic land-use and land-cover change to develop a complete understanding of the Earth system over time (Harrison et al. p.4; Stocker et al. p.6). These are followed by presentations of methods to achieve such reconstructions and their potential in the evaluation of model outputs (Morrison et al. p.8; Woodbridge et al. p.10; Marquer et al. p.12). Eight contributions on various aspects of land-use reconstructions based on archaeological and historical data, and the challenge of upscaling the information to global scale, follow. Lombardo et al. (p.14) provide an example of application of the LandCover6k global land-use classification in Latin America. Case studies from Africa (Boles et al. p.16), Japan (Bell et al. p.22) and Europe (Whitehouse et al. p.24) combine archaeology-based, land-use reconstructions with pollen-based estimates of land cover. Biagetti et al. (p.20) discuss past rain-fed agriculture in hyper-dry regions, and Widgren (p.18) presents maps of past land use in Africa. Antolín et al. (p.26) apply paleoecological and archaeological methods to reconstruct agricultural decision making in western Europe, Kolář et al. (p.30) use archaeological evidence to reconstruct past population dynamics and land use in central Europe, and Vander Linden et al. (p.28) discuss diffusion of early farming across Europe. The issue closes with examples of transient pollen-based REVEALS reconstructions of land-cover change in eastern China compared with archaeological data (Li et al. p.32), and the first synthesis of REVEALS-based reconstructions for the Northern Hemisphere (Dawson et al. p.34).

We hope this special issue will motivate more palynologists, archaeologists and historians to join the exciting opportunity of synthesizing the wealth of existing information on past land use and land cover in formats that are useful for the wider communities of social, environmental and Earth-system scientists.

\section{AFFILIATIONS}

'Department of Biology and Environmental Science, Linnaeus University, Kalmar, Sweden ${ }^{2}$ University Museum of Archaeology \& Anthropology, University of Pennsylvania, Philadelphia, USA ${ }^{3}$ Department of Humanities (CaSEs, ICREA), University Pompeu Fabra, Barcelona, Spain

${ }^{4}$ School of Geography, Earth and Environmental Sciences, Plymouth University, UK

\section{CONTACT}

Marie-José Gaillard: marie-jose.gaillard-lemdahı@Inu.se REFERENCES

Gaillard M-J et al. (2015) In: The BACC II Author Team (Eds) Second Assessment of Climate Change for the Baltic Sea Basin. Springer Open, 453-477

Klein Goldewijk K (2001) Glob Biogeochem Cy 15: 417-433

Klein Goldewijk K et al. (2017) Earth Syst Sci Data 9 927-953

Leemans R et al. (2000) PAGES news 8(3): 21-23 Oldfield F et al. (2000) PAGES news 8(3): 32 Strandberg G et al. (2014) Clim Past 10: 661-680

Sugita S (2007) Holocene 17: 229-241 